\title{
(t) \\ ENTREVISTA/INTERVIEW \\ A UNIVERSIDADE FEDERAL DO AMAZONAS (UFAM) E A SUA INSERÇÃO NA SOCIEDADE AMAZÔNICA
}

The Federal University of Amazonas (UFAM) and its insertion into the Amazonian Society

\section{Márcia Perales Mendes Silva ${ }^{1}$}

Entrevista realizada por

\section{Elenise Faria Scherer ${ }^{2}$}

A Universidade Federal do Amazonas (UFAM) é uma instituição centenária, criada em 1909. Sua comunidade universitária é constituída hoje por aproximadamente 33 mil pessoas, dentre os quais docentes, técnico-administrativos em educação e discentes, na capital (Manaus) e nos campi do interior do Estado (nos municípios de Coari, Humaitá, Benjamin Constant, Itacoatiara e Parintins). Pela primeira vez em sua história, a Universidade

${ }^{1}$ Doutora em Serviço Social pela PUCSP (200). Professora do Departamento de Serviço Social e dos Programas de Pós-Graduação em Sociedade e Cultura na Amazônia (PPGSCA) e em Serviço Social e Sustentabilidade na Amazônia da Universidade Federal do Amazonas. Reitora da UFAM.

${ }^{2}$ Professora e Pesquisadora do Departamento de Serviço Social, do Programa de Pós-Graduação em Sociedade e Cultura na Amazônia (PPGSCA) e do Programa de Ciência do Ambiente e Sustentabilidade na Amazonas (PPGSCASA), ambos da UFAM. E.mail:<elenise@internext.com.br>.

Temporalis, Brasilia (DF), ano 10, n.20, p.253-269, jul./dez. 2010. 
Federal do Amazonas é dirigida por uma mulher, eleita para a gestão do quatriênio 2009-2013. Márcia Perales Mendes Silva é assistente social e professora do curso de graduação em Serviço Social e dos Programas de Pós-Graduação em Serviço Social e Sustentabilidade na Amazônia (PPGSS) e Sociedade e Cultura no Amazonas (PPSCA), ambos da instituição. É líder do Grupo de Estudos e Pesquisas em Processos de Trabalho e Serviço Social na Amazônia (GETRA) desde 2001. Tem mestrado e doutorado em Serviço Social pelo Programa de Pós-Graduação da Pontifícia Universidade Católica de São Paulo (PUC) e foi Pró-reitora de Extensão e Interiorização da Ufam no quadriênio 2005/2009.

Em sua longa trajetória de educação superior no Estado do Amazonas, a UFAM consolidou-se como instituição amazônica, especialmente através da implementação de políticas institucionais, efetivadas por meio de suas ações de ensino, inovação tecnológica, pós-graduação, interiorização, extensão e desenvolvimento de projetos de investigação, com amplo apoio aos movimentos sociais.

A Reitora Márcia Perales Mendes Silva nos concedeu essa entrevista sobre a Ufam, seus projetos e seus desafios.

Logo após o seu doutoramento e seu retorno às atividades acadêmicas na Universidade Federal do Amazonas, especialmente ao seu departamento de origem, a senhora com seu grupo de pesquisa, o GETRA, se envolveu num projeto do Observatório Social da Central Única dos Trabalhadores (CUT). Como foi essa experiência? Quais os frutos desse processo em relação aos movimentos sociais, especialmente o sindical?

Márcia Perales - A proposta do Instituto Observatório Social/CUT/Unitrabalho teve caráter ousado, inovador e 


\section{temporalis}

comprometido com a classe trabalhadora. Desde o início, envolveu pesquisadores das Universidades Federais, estabelecendo uma parceria, a meu ver, muito importante, entre o movimento sindical e a academia.

As pesquisas realizadas possibilitaram investigar o nível de cumprimento, ou não, entre as Convenções selecionadas da Organização Internacional do Trabalhado (liberdade sindical e negociação coletiva, discriminação de gênero e raça, trabalho escravo, trabalho infantil e saúde e segurança no trabalho) e a realidade das empresas multinacionais signatárias, cujas filiais estavam implantadas em países diversos.

Na região norte do Brasil, coordenei as pesquisas realizadas em três multinacionais instaladas no Pólo Industrial de Manaus (Moto Honda, Nokia e Philips), chegando, na última delas, a pesquisar os níveis I e II de sua cadeia produtiva.

Adentrar ao espaço das empresas nunca foi tarefa fácil. Conseguir a adesão dos trabalhadores ao projeto, mesmo com o apoio permanente dos sindicatos envolvidos, também era um grande desafio, uma vez que já havia resistência dos mesmos em participar de pesquisas cujos resultados a eles nunca retornavam, parecendo, portanto, uma ação inócua e sem consequência positiva. Entretanto, vencida aquela barreira inicial, a relação que se estabeleceu entre pesquisadores e pesquisados foi de uma riqueza indescritível, não somente em função dos laços de parceria que se criavam, mas, principalmente, pela possibilidade de serem concretamente qualificadas as relações de trabalho por meio de análises fundamentadas cientificamente.

Vivemos, naquele momento, situações politicamente preciosas: numa empresa finlandesa, por exemplo, identificamos indícios de 


\section{temporolis}

discriminação de gênero, o que soou como uma bomba em seu país de origem, ao ponto do staff finlandês ter que se deslocar a Manaus para negociar medidas corretivas, embora tentassem (tática empresarial?) sempre desqualificar os relatórios; em uma empresa holandesa, outro exemplo muito interessante, visto que, depois de muita negociação entre a direção, o sindicato e a equipe de pesquisa, todas as linhas de produção pararam por dez minutos para que nós, pesquisadores, apresentássemos a pesquisa, explicássemos de que forma ela poderia ajudá-los e também para que solicitássemos a participação de todos. Foi uma imagem impressionante ver as linhas de produção de uma grande empresa paradas para que a equipe de pesquisadores do Observatório Social pudesse se dirigir aos trabalhadores! Mas foi também interessante lidar com questionamentos sobre o nosso " [...] excesso de euforia somente pela rápida parada de linhas de produção de uma empresa". O significado político da paralisação poderia, de fato, ser irrelevante para os que não dimensionam criticamente a relação estabelecida entre o capital e o trabalho nas sociedades capitalistas. Era uma inquestionável conquista do movimento sindical!

Concluídos os relatórios, pesquisadores e sindicatos convocavam os trabalhadores, especialmente os participantes da pesquisa, para conhecê-los. A partir daí, as negociações realizadas entre empresa e sindicato tinham como base de sustentação os relatórios de pesquisa, amplamente divulgados na mídia falada e escrita e disponibilizados no sítio do Observatório Social. As negociações, majoritariamente tensionadas, não impediram melhorias concretas no cotidiano fabril, principalmente nas condições de trabalho (saúde ocupacional e segurança no trabalho) e no exercício da liberdade sindical e negociação coletiva. 


\section{temporolis}

A reforma política está na ordem do dia. Um dos temas dessa reforma é a democratização do Estado brasileiro que, apesar de ter avançado, ainda guarda resquícios de uma forma oligárquica e autoritária. As universidades brasileiras têm contribuído enormemente com esse processo de democratização da sociedade, isto é um fato inegável, sobretudo a partir dos processos democráticos criados com a eleição para os reitores e demais cargos no interior das IES. Além disso, as universidades, em face de sua estrutura, ainda não atuam de forma desejável, se analisados os vínculos de contribuição existentes na relação Estado-Sociedade. Isto supõe aproximação com os movimentos sociais. Como uma Universidade centenária tem ocupado o espaço na sociedade amazonense?

Márcia Perales - Há muitas maneiras de contribuir com o fortalecimento da democracia. A Universidade é, por natureza, um espaço privilegiado e fecundo cujas razões envolvem, simultaneamente, a elaboração de reflexões críticas fundamentadas e ações sócio-acadêmicas efetivas. Exemplo disso é o desafio atual de revisar e atualizar o Estatuto e Regimento Geral da UFAM, por meio de um processo estatuinte, amplamente democrático, em franca implementação, pois, a partir de avaliações se chegou à conclusão de que a estrutura jurídicopedagógica vigente da UFAM apresenta aspectos obsoletos, incoerentes e redundantes, impostos pelas inequívocas transformações contemporâneas.

A Universidade Federal do Amazonas está no cerne de tais transformações, ou seja, também mudou porque esta instituição não está encapsulada numa redoma, mas inserida organicamente no seio da sociedade, o que exige um novo olhar para as suas estruturas e dinâmicas institucionais. De fato, a ousadia de encarar tal empreitada é fruto de decisão política de seu Conselho 


\section{temporalis}

Universitário, que reconheceu fragilidades e considerou os anseios da comunidade universitária, a qual, longe de qualquer resistência, está revendo - com sabedoria, pertinência e consequência - as estruturas e dinâmicas internas da UFAM, em vista do cumprimento de suas funções sociais mais fundamentais. Duas claras demonstrações de que se compreende que: a democracia é um processo construído e, por isso, deve ser realimentado permanentemente; a comunidade universitária é pulsante e não está disposta a se arriscar ao indesejável anacronismo histórico.

É preciso estar atento para o fato de que todo o aparato técnicocientífico exige o abalizado aperfeiçoamento das formações acadêmicas, garantindo-se, de forma intransigente, a organicidade entre as dimensões técnica e cidadã. Para tanto, as funções precípuas da Universidade é que devem delimitar as suas estruturas, pois os meios não podem engessar os fins e as estruturas não podem definir as suas funções. Daí a rejeição a uma arquitetura imposta e a defesa de uma arquitetura coletivamente construída, concretizada para sustentar os avanços do conhecimento e seu benefício a toda a sociedade.

Caminhando em direção ao fortalecimento democrático, à transparência pública e à inclusão social, em 2009 e 2010, respectivamente, a UFAM aprovou a criação da Ouvidoria Geral e adotou a gratuidade para todos os alunos dos 61 municípios do interior do Estado, oriundos das escolas públicas e inscritos para concorrer ao Processo Seletivo Contínuo (PSC). Decisões, estas, importantes em direção à Universidade que queremos. O fato é que reinventar a Universidade Federal do Amazonas implica sua revitalização como desafio cotidiano de todos nós, o que remete indubitavelmente ao respeito, à postura ética e ao espírito público, ancorados na luminosidade democrática e no olhar em direção a uma instituição ambientalmente responsável, que atue em favor 


\section{temporolis}

das gerações presente e futura. A referência balizadora é a busca constante por uma Universidade com Excelência Acadêmica $e$ Compromisso Social - científica e pedagogicamente producente; socialmente ágil e comprometida, intransigentemente competente, plural, ousada e democrática.

A educação e a cultura são elementos constitutivos da ideia de cidadania. As instituições universitárias não podem se furtar da ideia da democracia e de democratização do saber. A partir deste corolário, as universidades da Amazônia têm tido uma presença histórica e ativa por meio dos seus campi na vida amazônica, seja por meio do ensino, da extensão, da pesquisa. Como a Universidade tem avançado nesse sentido?

Márcia Perales - O desafio de interiorizar a Universidade Federal do Amazonas nunca foi missão fácil, sobretudo se considerarmos a sua inserção no maior estado brasileiro, as suas características geográficas, étnicas, econômicas, políticas e, por conseguinte, todas as dificuldades daí advindas. O reconhecimento de tais singularidades e a clareza da missão que a UFAM assumiu, fundamentam a convicção de que a sua interiorização é muito mais que democratizar relações e saberes. Indo mais além, significa possibilitar a jovens e adultos, cujos pais nunca puderam cursar uma Universidade, a projeção de perspectivas antes apenas sonhadas; implica a ampliação de visões de homem, de mundo, de sociedade, de presente e de futuro; redunda na implementação de uma nova dinâmica sócio-econômica e política, não apenas para os que ingressaram na Universidade, mas para a comunidade como um todo, pois, uma universidade pública federal é, e será sempre, indutora de desenvolvimento sócio-econômico. Enfim, interiorizar, além de significar a concretização de sonhos, sonhados coletivamente, implica a concretização de um direito adquirido e conquistado.

Temporalis, Brasilia (DF), ano 10, n.20, p.253-269, jul./dez. 2010. 
Os avanços da UFAM nesta direção foram intensificados a partir de 2005, com a implantação do Programa Ufam Multicampi - uma iniciativa do Governo Federal/MEC -, que propiciou uma verdadeira ruptura entre o modelo anterior de interiorização e o modelo atual. Enquanto o primeiro permitiu o oferecimento de cursos de graduação no interior do estado, por meio de disciplinas modulares - realizadas majoritariamente em parceria com o poder público municipal, com o saldo, entre 1980 e 2005, de mais de seis mil novos profissionais -, o modelo atual criou uma estrutura acadêmica própria e permanente nos municípios de Coari, Humaitá, Benjamin Constant, Itacoatiara e Parintins. Para tanto, houve concurso público para mais de quinhentos novos servidores federais (docentes e técnico-administrativos em educação) para as cinco novas Unidades Acadêmicas Permanentes implantadas. No total foram abertos trinta e dois cursos permanentes de gradução/licenciatura nestes municípios, estruturados por meio da concentração de áreas temáticas, além de novas edificações, aquisição de equipamentos e estruturação de laboratórios. Hoje, mais de sete mil jovens estão cursando o ensino superior, envolvendo-se em pesquisa e extensão, sem precisar migrar para Manaus, o que acontecia em condições adversas para a maioria, sem contar aqueles que sequer poderiam tentar essa empreitada.

Com a implantação do Programa Ufam Multicampi, a interiorização na UFAM avançou e com ela vem sendo reiterado o princípio da indissociabilidade entre ensino, pesquisa e extensão e do compromisso sócio-acadêmico. Apesar de se tratar de um processo ainda tão jovem - seis anos de existência -, vale destacar o desenvolvimento de um significativo número de projetos de pesquisa e de extensão, envolvendo temáticas voltadas para formação de professores, discriminação contra mulheres, direitos de crianças e adolescentes, organização e inserção produtiva etc., consolidados por meio de programas institucionais como o PIBIC, 


\section{temporalis}

PIBEX e o PACE. Com tais produções, a UFAM vai trilhando um caminho profícuo e promissor.

Sem menosprezar as dificuldades inerentes à implantação de um Programa de interiorização dessa envergadura, é possível afirmar que a cartografia da interiorização no Amazonas mudou e a comunidade da UFAM, com muita competência, vem contribuindo para positivas alterações no mapa da interiorização de nosso Estado. Entretanto, é necessário continuar avançando no aprimoramento deste processo, consolidando-o e ampliando-o, tendo sempre presente que há muitos desafios a serem enfrentados, como a captação e fixação de recursos humanos, por exemplo. Mais ainda: é preciso responder às demandas daqueles municípios/mesorregiões que, por reconhecerem o que $a$ Universidade Federal do Amazonas representa, solicitam cada vez mais que a sua presença se concretize forma estável e permanente.

O Amazonas é o estado da Federação que congrega mais de 40 etnias em seu território. A senhora poderia falar dos projetos desenvolvidos de educação, formação. Quais são as atividades desenvolvidas com etnias?Qual a contribuição em relação à educação indígena? Como ocorreu a inserção no interior do Estado e a aproximação com os movimentos sociais, especialmente os indígenas?

Márcia Perales - A riqueza e a diversidade étnicas do nosso estado são, de fato, exponenciais. A UFAM desenvolve diversas ações voltadas para as comunidades indígenas desde 1992, quando foram iniciadas atividades regulares na região do Alto Rio Negro, especialmente no município de São Gabriel da Cachoeira, com a realização do curso de Licenciatura em Filosofia. Mas, em um estado onde existem 74 povos indígenas, as ações foram

Temporalis, Brasilia (DF), ano 10, n.20, p.253-269, jul./dez. 2010. 


\section{temporolis}

intensificadas frente às reivindicações de lideranças, associações e estudantes por cursos específicos. Dois exemplos emblemáticos são os de São Gabriel da Cachoeira e da Licenciatura Mura.

Em São Gabriel da Cachoeira, município que é constituído por 23 povos indígenas, de cinco famílias linguísticas diferentes (Tukano Oriental, Maku, Aruak, Yanomami e Nheengatu), foi iniciado, em 2010, o projeto DabuKuri: Gestão territorial, sustentabilidade e valorização do conhecimento e de tecnologias sociais dos povos indígenas, com o apoio do Ministério de Ciência e Tecnologia (MCT).

Entretanto, as discussões sobre a necessidade de implantação de uma Universidade Indígena para os Povos do Alto Rio Negro foram iniciadas em 2004 e continua sendo tema de seminários e encontros realizados conjuntamente pela UFAM e várias organizações indígenas.

Os avanços no Alto Rio Negro já são muitos: já foram realizados seis cursos de licenciatura e uma especialização lato sensu, com o saldo de 430 profissionais formados, dos quais 95\% são indígenas. Está em plena execução a Licenciatura Indígena Políticas Educacionais e Desenvolvimento Sustentável, bem como a elaboração do projeto de construção do Centro Universitário Indígena do Alto Rio Negro que será construído em São Gabriel da Cachoeira e viabilizado pelo Parque Científico Tecnológico para Inclusão Social da UFAM, criado em 2010.

Todas essas ações sinalizam o envolvimento institucional da UFAM em direção ao fortalecimento étnico cultural destes povos, por meio de alternativas sustentáveis que contenham o êxodo indígena das comunidades e lhes permitam reverter o processo de 


\section{temporalis}

colonização de conhecimento a que foram historicamente submetidos.

Vale destacar que todos os passos empreendidos têm como referência o princípio da valorização das territorialidades linguísticas pelas calhas de rios, de acordo com as famílias linguísticas, e o respeito à Lei de Co-oficialização das Línguas Indígenas Tukano, Baniwa e Nheengatu, que outorgou a São Gabriel da Cachoeira a condição de primeiro município brasileiro a ter línguas indígenas oficializadas, ao lado do português.

Reiterando a necessidade de um cenário de descolonização do saber, regido pela pluralidade e pelo reconhecimento da autodeterminação dos povos indígenas, o curso de Licenciatura Específica Formação de Professores Indígenas também é emblemático. Trata-se de um curso regular/modular, com duração de cinco anos, que busca formar, em nível superior, numa perspectiva intercultural e interdisciplinar, professores indígenas para atuar na $2^{\mathrm{a}}$ etapa do Ensino Fundamental e no Ensino Médio, nas escolas indígenas, com habilitação plena nas áreas de Ciências Humanas e Sociais; Ciências Exatas e Biológicas; Letras e Artes.

Atualmente, o curso conta com uma turma que atende alunos do povo Mura (Autazes - AM), em funcionamento desde 2008, e uma turma destinada aos alunos do povo Mundurukú (AM/PA), em funcionamento desde março 2011. Existe ainda a previsão de iniciar mais uma turma destinada ao povo Sateré-Mawé (Terra Indígena Andirá-Marau), a partir do segundo semestre de 2011.

Os Cursos têm como eixos centrais a pesquisa e o Projeto PolíticoPedagógico das Escolas Indígenas de cada povo e é resultante da demanda de professores indígenas, articulados pela Organização dos Professores Indígenas Mura (OPIM), que buscam dar

Temporalis, Brasilia (DF), ano 10, n.20, p.253-269, jul./dez. 2010. 
continuidade à sua formação, a qual se entrecruza com a trajetória do grupo de pesquisa Formação do(a) educador(a) frente aos desafios amazônicos, vinculado ao Programa de Pós-Graduação em Educação, da Faculdade de Educação/UFAM, que desde 2002 desenvolve atividades de pesquisa e formação continuada, junto aos professores Mura do Município de Autazes/AM.

A Amazônia e sua rica e complexa sociobiodiversidade é considerada um paraíso para a genética, e pesquisas biomédicas, espaço para experiências sustentáveis e cooperação internacional. Para as ciências humanas e sociais, a região tem se constituído num espaço amplo para os estudos sobre as cidades, políticas territoriais, seus povos tradicionais e modos de vida. Como a Universidade vem se estabelecendo frente às demandas colocadas pelos movimentos sociais (ambientalistas ou não)?

Marcia Perales - A Universidade Federal do Amazonas tem uma longa e relevante história de envolvimento com as questões ligadas à megadiversidade biológica e à riquíssima sociodiversidade que refletem a fascinante singularidade da Amazônia. Trata-se de uma singularidade que se deixa melhor perceber, no plano da megadiversidade biológica, através de estimativas cientificamente fundamentadas e frequentemente ampliadas por novos estudos e descobertas - como as que se seguem: $68 \%$ das florestas tropicais e $20 \%$ da água doce do planeta, 15.000 espécies vegetais, 500 espécies de mamíferos, 500 espécies de anfíbios, 400 espécies de répteis, 3.000 espécies de peixes, 1.600 espécies de aves, centenas de milhares de espécies de insetos, incontáveis espécies de microrganismos.

No que se refere à sociodiversidade, além dos contingentes africanos, europeus e asiáticos, muitos povos indígenas, com suas culturas milenares e que sobreviveram ao processo de extinção 


\section{temporalis}

que se abateu sobre eles ao longo de mais de quatrocentos anos, ainda representam hoje uma parcela extraordinariamente importante da população amazônica. Tanto que, além dos mais de 70 grupos indígenas isolados (que se estima existir principalmente na Amazônia brasileira), aqui ainda sobrevivem pelo menos 62 etnias indígenas - sendo que em boa parte delas há falantes de suas línguas nativas.

Então, em nome da salvaguarda dessa complexa Amazônia, onde o destino dos povos e da floresta manifesta-se cronicamente compartilhando os sobressaltos e as consequências da devastação, da grilagem, dos assassinatos no campo e do avanço desordenado e irresponsável da soja e da agropecuária, os docentes, técnicos e discentes da UFAM vêm participando e, em muitos casos, liderando movimentos ambientalistas, em defesa dos povos indígenas e das populações tradicionais da Amazônia, conjugando a militância com uma crescente produção científica voltada para as potencialidades locais e socializada através de centenas de projetos de extensão anuais e semestrais, com um público alvo de milhares de comunitários que vêm tendo na Universidade uma parceira confiável e compromissada como reflexo do ethos que esta Instituição consolidou, com muitos sacrifícios e com reconhecida competência, superando grandes obstáculos ao longo de um século. Portanto, uma Universidade que há muito deixou de ser apenas mais uma universidade do Amazonas para tornar-se, efetivamente, uma universidade amazônica.

Uma Universidade centenária do porte da UFAM: como esta instituição tem conduzido a sua política de ciência e tecnologia, sobretudo no que diz respeito a tecnologias sociais para as populações tradicionais na Amazônia?

Temporalis, Brasilia (DF), ano 10, n.20, p.253-269, jul./dez. 2010. 


\section{temporolis}

Márcia Perales - Primeiramente, é necessário destacar que o debate sobre as tecnologias sociais e as populações tradicionais está em pauta permanentemente na UFAM, pois, apesar dos importantes passos envidados, temos muito a avançar coletivamente. A nossa inserção geográfica e o reconhecimento da complexa sociobiodiversidade que a envolve são fatores determinantes para intensificarmos discussões, ações de extensão e de pesquisa voltadas para as populações tradicionais. Coerentemente, a UFAM possui um leque de Políticas de Extensão e de Pesquisa, as quais sinalizam a necessidade de ação e investigação voltadas tanto para as Tecnologias Convencionais como para as Tecnologias Sociais. Estas últimas, por sua vez, se orientam a partir de um conjunto de diretrizes, das quais se sobressaem a necessidade do reconhecimento dos saberes tradicionais (e da grande relevância das suas interações com o saber acadêmico) e o incentivo ao debate permanente em torno da realidade amazônica, propiciando a implementação de ações correspondentes às demandas.

Nesta direção, várias pesquisas e ações de extensão são desenvolvidas, com financiamento externo e interno, em que se destacam inúmeros eventos que têm centralizado esta temática, como o Fórum de Tecnologia Social da UFAM, além da participação dos Grupos de Pesquisa da UFAM.

Parece fato que uma ação responsável por consolidar o envolvimento e reconhecimento pela UFAM em relação à relevância das Tecnologias Sociais é, sem dúvida, a aprovação, no seu Conselho Superior de Administração, do Parque Científico Tecnológico para Inclusão Social: prática de inovação articulando conhecimentos técnicos científicos e populares na Amazônia (PCTIS). Há que se admitir que tal conquista tornou-se um marco institucional em direção à estruturação de uma Rede de Pesquisa, 


\section{temporalis}

Extensão e Inovação Tecnológica voltada para inclusão social com firme propósito de garantir uma política de sustentabilidade sócioeconômica.

Financiado pelo Ministério de Ciência e Tecnologia, Secretaria de Ciência e Tecnologia para Inclusão Social e sob a coordenação do Núcleo de Inovação Tecnológica (NIT), o PCTIS abarca ações empreendidas pela Rede e está direcionado para a promoção da inclusão social dos diversos segmentos que se encontram em situação de risco e de vulnerabilidade social e ambiental, e estão envolvidos direta e indiretamente na sua estrutura, o que vem possibilitando a criação de oportunidades de acesso para o usufruto de Bens e Serviços Sociais e adoção de práticas sustentáveis de geração de renda via Pesquisa, Desenvolvimento e Inovação ( $P, D \& 1)$. Este projeto representa um significativo avanço em direção à construção de mecanismos em termos de políticas inclusivas, afirmativas de cidadania, criação de espaços de participação social via Inovação Social e Cultural, originária da demanda da sociedade civil organizada para enfrentar os dilemas e desafios vigentes na região.

É fato que, nessa empreitada, tal modalidade de inovação efetiva-se a partir de uma série de procedimentos inovadores que envolvem: a adoção de um novo modelo de produção cientifica e de aplicação da tecnologia; o fomento a uma articulação e interação intersetorial e interdisciplinar na produção, no desenvolvimento e na difusão de tecnologias; o fortalecimento da democracia e da soberania em diferentes níveis territoriais; novas oportunidades, cultivando novas formas de cooperação; o espaço para novos significados no que tange às tecnologias em determinadas áreas; a cultura como referência, respeitando-a em seus saberes, com a valorização de seus símbolos e artefatos, tornando-a rentável, agregando-lhe valor e conduzindo seus protagonistas a patamares de melhores condições de vida, saúde e educação.

Temporalis, Brasilia (DF), ano 10, n.20, p.253-269, jul./dez. 2010. 


\section{temporalis}

O PCTIS conta com a participação de mais de duzentos pesquisadores da UFAM (da capital e do interior do Estado), aproximadamente quarenta parceiros, e deverá atingir aproximadamente oitocentas comunidades, sendo, destas, quinhentas indígenas. Trata-se de mais um desafio coletivo muito bem-vindo!

\section{Quais as suas perspectivas futuras para a Ufam? O que destacaria para finalizar esse depoimento?}

Márcia Perales - As perspectivas são extremamente positivas, tanto pelas ações já em curso como pelas ações a serem iniciadas. A UFAM vem crescendo sistematicamente, o que implica a ampliação real de seus grupos de pesquisa, programas e projetos de extensão, cursos de graduação e pós-graduação, servidores titulados, ações de assessoria e consultoria etc. Ao defender de forma intransigente que uma instituição pública federal não pode se furtar em ser centro de excelência e, concomitantemente, comprometer-se com a sociedade que a financia, a UFAM direciona-se fortemente para a inovação tecnológica, demarcando seu perfil de Universidade Amazônica, ética, acadêmica, social e ambientalmente responsável. Ao se fazer presente, seja na condição de parceira - nos inúmeros projetos e programas em conjunto com os governos federal, estadual e social e empresas -, seja na condição de autora e protagonista nas diversas áreas do conhecimento, a UFAM ratifica a assunção da missão que lhe cabe, resguardando seus princípios, natureza e espaços de atuação.

O mais importante a ser ressaltado é que as conquistas só podem se tornar concretas em decorrência de enorme esforço institucional que envolve gestores, docentes, técnicos administrativos em educação e discentes, os quais, juntos, credenciam a nossa Instituição a consolidar um perfil amazônico de excelência, colocando-a numa posição de 


\section{temporalis}

destaque no Estado do Amazonas, fundamentalmente na região Norte, mas também no Brasil e no exterior.

Sem jamais escamotear as dificuldades ou secundarizar novos desafios, pois estes também são muitos e precisam ser enfrentados. Ou, melhor dizendo, já que se quer uma instituição cada vez melhor, torna-se fundamental, portanto, fortalecer o entendimento de que somos, na totalidade, uma Instituição única e, em que pese o teor da sua singularidade, ela é constituída por pessoas com visões heterogêneas, de conteúdos e formas diversos, mas que buscam, em última instância, o fortalecimento desta que é inegavelmente o Nosso Maior Patrimônio.

Nessa direção, ao mesmo tempo em que o vínculo que une a universidade e a sociedade é intensificado, as ações desenvolvidas pela UFAM estimulam a interdisciplinaridade, a democratização das relações entre os alunos universitários e entre a população não universitária, contribuindo para que a formação acadêmica seja acompanhada por uma atitude ética, cidadã, solidária e comprometida com as mudanças necessárias diante das questões sociais emergentes. Desafios a serem por nós enfrentados coletivamente!

Por tudo isso, creio que os avanços correspondam à força motriz responsável por gerar a continuidade e a competência necessárias para enfrentarmos criticamente as dificuldades e os desafios, sejam eles mais novos ou mais antigos, e, portanto, devem ser encarados com postura crítica e propositiva - até porque a crítica pela crítica é inócua. A propósito, ao exercitar a missão para qual a UFAM se volta, a conquista do trabalho de construção coletiva deve constituir-se num verdadeiro legado de aprimoramento do exercício sócio-pedagógico que: constrói, na ousadia; impulsiona, na determinação; realiza, no compromisso; humaniza, na competência; e, por fim, que qualifica, na utopia que torna viva a instituição.

Temporalis, Brasilia (DF), ano 10, n.20, p.253-269, jul./dez. 2010. 
